\title{
LA MAGIA EN LA TRAGEDIA GRIEGA
}

\author{
M. ${ }^{a}$ Teresa Molinos Tejada - Manuel García Teijeiro \\ Universidad de Valladolid \\ molinos@fyl.uva.es - manuel@fyl.uva.es
}

\begin{abstract}
RESUMEN
La tragedia griega clásica no se caracteriza por tener gran interés por la magia. Hay, sin embargo, pasajes importantes sobre ella, como las escenas de necromancia en Esquilo, ciertos episodios de la carrera de Medea como maga, el supuesto encantamiento erótico de Deyanira o el himno que ata de las Euménides. Hay también alusiones más escuetas a esas creencias y prácticas. En el Hipólito de Eurípides las referencias a los hechizos amorosos cumplen una función importante en la caracterización de Fedra y de su nodriza.
\end{abstract}

PALABRAS ClAVE: Tragedia griega, magia, necromancia.

\section{MAGIC IN GREEK TRAGEDY}

\section{ABSTRACT}

Classic Greek tragedy is not characterized by a great interest in magic. Important passages on this subject can be found, however, such as the scenes of necromancy in Aeschylus, some episodes of the career of Medea as a magician, the supposed erotic charm of Deianira or the binding hymn of the Eumenides. There are also brief allusions to such beliefs and practices. In Euripides's Hippolytus the references to love magic play an important role in characterizing Phaedra and her nurse.

KEYWORDS: Greek tragedy, magic, necromancy.

No hay en la tragedia griega especial interés por los temas mágicos, aunque no faltan en ella. Como ocurre en el mito y en la epopeya, de donde toma casi siempre sus argumentos, no se complace en explotar las posibilidades que ofrecían, como hizo después la literatura helenística y romana. Selecciona lo que es pertinente al drama y prescinde de lo más llamativo y menos compatible con la seriedad, solemnidad, si queremos, del género trágico. Ese ideal de selección se aprecia muy bien si se considera cómo trata a los dos personajes que en la tradición literaria encarnaban la plenitud de los poderes mágicos ${ }^{1}$. Ambos son femeninos y pertenecen al mundo de la épica, Circe al de la Odisea y Medea al de los Argonautas. Hay entre ellas afinidades, pues las dos descienden del Sol: la primera es hija suya, la segunda nieta, de modo que Medea es sobrina de Circe, pero también una diferencia muy importante, esta es una diosa, aquella una mujer, más apta, por tanto, para experimentar las pasiones humanas. 
En la aventura de Ulises, Circe convierte a los hombres en animales dándoles a beber una pócima y tocándolos después con su bastón, antecedente de la varita mágica; invita a acostarse con ella, pero quita al hombre su virilidad; sabe a dónde hay que ir y cómo hay que proceder para evocar el alma de un muerto y preguntarle lo que se desea saber. La tragedia tomó de la saga el tema de la consulta nigromántica (cf. Macías Otero, 2015). Conservamos fragmentos de una de Esquilo,

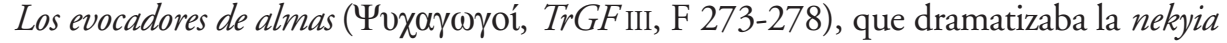
del canto XI de la Odisea ${ }^{2}$ y otra del mismo autor, que por excepción trata un tema contemporáneo, Los Persas, contiene la famosa evocación del alma del rey muerto Darío. La escena tuvo que ser impresionante, pero no era propiamente de nigromancia. La acción sucede a pleno día, delante de la tumba. La reina madre hace la ofrenda incruenta y el coro de nobles ancianos ruega a los dioses subterráneos que envíen a la sombra de Darío. Cantan un himno invocándola e insistiendo en los ruegos para que le sea permitido acudir (633-680). Cuando se presenta, la anciana reina le explica lo ocurrido. Darío escucha y aconseja lo que debe hacerse en el futuro. El pasaje tiene más de religión que de magia ${ }^{3}$.

Medea fue personaje favorito de la tragedia griega ${ }^{4}$. El pasaje de colorido mágico más vivo se halla en el fragmento 534 de Las cortadoras de raíces de Sófocles ('Picotó $\mu$ ol, $\operatorname{Tr} G F$ IV, F 534-536): Medea, mirando hacia atrás, desnuda, entre alaridos, corta raíces con hoces de bronce, recoge el jugo blancuzco que destilan en recipientes del mismo metal y guarda lo cortado en cestas bien tapadas. La relación entre el bronce y la virtud de las plantas, la precaución de apartar la mirada, la desnudez y los gritos apuntan claramente a un ritual mágico, y los otros dos fragmentos conservados de la tragedia señalan en la misma dirección: en el 535 las mujeres del coro mencionan a la diosa Hécate, y el 536, muy breve, habla de una figurita que se consume en el fuego. El tema de esta tragedia podría referirse a los hechos ocurridos en Cólquide, cuando Medea ayudó a Jasón con sus hechizos a conquistar el vellocino de oro, asunto que el mismo Sófocles abordó en otra de sus obras, Las mujeres de Cólqui-

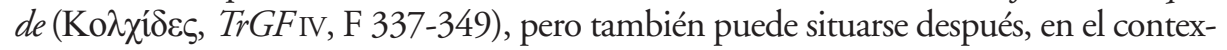
to del episodio de Yolco, donde Medea engañó a las hijas de Pelias con un cocimiento

${ }^{1}$ Sobre la figura de la maga en la literatura griega, cf. García Teijeiro, 2002 y 2005.

${ }^{2}$ No es seguro que formara una trilogía con Penélope y Osteologoi, acompañados del drama satírico Circe, bibliografía reciente en Wright, 2018: 53. Sobre ciertas peculiaridades estilísticas de la invocación, Romilly, 1975: 15-18.

${ }^{3}$ Basándose en el comienzo del himno (633-639), Headlam, 1902, propuso, sin embargo, que los ancianos del coro eran en realidad magos y que en su evocación debía de haber fórmulas mágicas en lenguaje especial. Crítica en Lawson, 1934; Rose, 1950; Broadhead, 1960: 305-309. Opinión más matizada en Jouan, 1981. Cf. Ogden, 2001: 129 s.

${ }^{4}$ Cf. Eitrem, 1941: 47. Wright, 2016: 204, da una lista de tragedias clásicas que lo utilizaron, y en 2018: 227-236, discute los diferentes puntos de vista con que lo hicieron. También la tragedia posterior, el drama satírico, la comedia y la farsa dórica se interesaron por Medea, vid. Melero, 1996. 
mágico que tenía la virtud de rejuvenecer, tema de la primera tragedia de Eurípides,

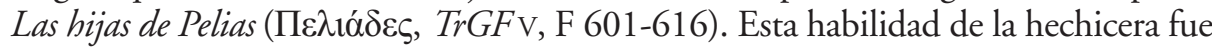
también tema de una tragedia o drama satírico de Esquilo, Las nodrizas (Tpopoí, $\operatorname{Tr} G F$ III, F 246 a-d). Allí eran las nodrizas de Dioniso y sus maridos quienes conseguían la juventud por medio de la cocción mágicas.

La única tragedia sobre Medea que tenemos completa es la Medea de Eurípides. El personaje es allí una mujer de formidable carácter, sin que el poeta ponga énfasis en su condición de hechicera. Las alusiones a su fama hacen hincapié en sus conocimientos y no en sus poderes mágicos (285, 292-305, 401-403, 539 s., 718). Es experta en $\varphi \alpha ́ p \mu \alpha \kappa \alpha$, en drogas que pueden ser medicina y también veneno (385, 789, 805 s.). Las referencias a sus encantamientos del pasado son solo implícitas, cuando ella recuerda a Jasón en amargo reproche cómo le había ayudado en Cólquide a uncir los toros que exhalaban fuego, a sembrar el campo de muerte (478 s.) y a matar al dragón que custodiaba el vellocino de oro (480-482); cómo después, en Yolco, causó la muerte de Pelias por medio de sus propias hijas (486 s., cf. 504 s.). El carro alado sobre el que aparece en la escena final no es un vehículo mágico, sino un regalo de su abuelo el Sol' ${ }^{6}$. Tampoco es necesario suponer hechizados la corona y el peplo que envía a su rival Creúsa, la nueva esposa de Jasón para que le causen una muerte horrible (784 ss., 949 ss., 1136 ss.; cf. Pozzi, 1994). Que la corona sea una fuente de fuego (1186 s.) se explica bien, puesto que era regalo del Sol. El vestido estaría impregnado de un poderoso veneno (cf. 1201), cuya naturaleza y origen el poeta no especifica. Recuerda a aquel que causó la muerte de Heracles con tormentos muy semejantes. Sófocles trató el tema en las Traquinias. Allí es la ponzoña de la hidra de Lerna, mezclada con la sangre del centauro Neso, la causa que produjo el terrible efecto. En esta tragedia también es una mujer quien envía el fatal regalo del $\pi \varepsilon ́ \pi \lambda \circ \varsigma$ impregnado en veneno que matará al primero que se lo ponga, por eso hay que procu-

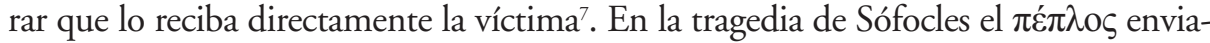
do por Deyanira no es una prenda femenina, sino una túnica ${ }^{8}$ para su marido Heracles, con la intención no de matarlo, sino de recuperar su amor', que el héroe ha puesto

${ }^{5}$ Sobre estos rejuvenecimientos de Medea, cf. Ogden, 2001: 206 s.

${ }^{6}$ El texto de Eurípides no dice que tirasen de él dragones alados, pero el detalle debió de formar parte de la escenificación antigua, puesto que se encuentra en la primera hypothesis (7-9), en los escolios y en las representaciones artísticas a partir de c. 400 a. C. (Schmidt, 1992: nno. 34-48, 396 s.).

${ }_{7}$ Tra. 604-609: nadie debe ponerse la túnica antes que Heracles, también hay que evitar que le dé la luz. Med. 972 s.: Medea manda a sus hijos que den el regalo directamente a su rival, pues ante todo importa que lo reciba ella en sus manos.

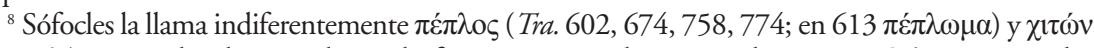
$(580,612,769)$. Eurípides designa el vestido femenino enviado por Medea como $\pi \varepsilon ́ \pi \lambda ం \varsigma$ en singular $($ Med. 786 = 949) o en plural $(1159,1188,1214)$.

${ }^{9}$ Errandonea, 1927, propuso que Deyanira envió la túnica envenenada sabiendo que causaría la muerte de Heracles y urdió el relato del engaño del centauro para justificarse. Insistió en esta propuesta en trabajos posteriores y obtuvo algunas adhesiones, vid. Faraone, 1994 y 1949: 110-119. 
en otra. Como ella misma explica, en cierta ocasión el centauro intentó forzarla, Heracles oyó sus gritos y lo atravesó con una flecha impregnada con el veneno de la hidra. Moribundo, Neso le dijo que si recogía la sangre que brotaba de su herida, obtendría un poderoso filtro ${ }^{10}$, que obligaría a Heracles a no amar a ninguna mujer más que a ella (Tra. 569-577). El poeta toca aquí el tema de la magia, pero solo de modo superficial, puesto que la virtud del supuesto filtro residía no en ningún ritual ni en fórmulas mágicas ${ }^{11}$, sino en la calidad de la sangre del centauro, vertida en pleno arrebato de pasión por la mujer ${ }^{12}$.

En las Euménides de Esquilo la magia aparece en un contexto muy diferente. El coro de esta tragedia está formado por espíritus infernales que persiguen a quien haya matado a un pariente de su misma sangre. Son las Erinis, las Furias, acosadoras sin descanso del asesino, personificaciones de la venganza y del remordimiento. El poeta las representó con oscuros ropajes y cabellera formada por serpientes ${ }^{13}$. Testimonios tardíos dicen que la aparición, uno por uno, de estos terroríficos personajes en el escenario sobrecogió de tal modo a los espectadores que los niños se desmayaban y las embarazadas abortaron ${ }^{14}$. Alarmado, el Estado habría reducido por ley el número de coreutas ${ }^{15}$. En la tragedia este coro de Furias encuentra a su víctima, Orestes, en la colina del Areópago de Atenas, a donde había acudido, por mandato de Apolo, para buscar la protección de Atenea. Allí entona contra él un cántico maléfico, un "cántico que ata" ("̋ $\mu v o \varsigma \delta \delta ́ \sigma \mu 10 \varsigma$ ) lo llama el corifeo (306), expresión que el coro repite en su estribillo $(331-333=344-346)^{16}$. Los pasos de danza que acompañaban al canto pueden interpretarse como una especie de ritual y la noción de atar, repetida en el cántico, tiene especial relevancia en el contexto, puesto que

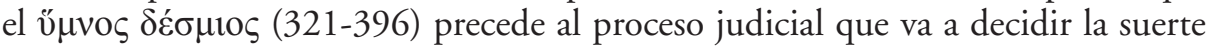

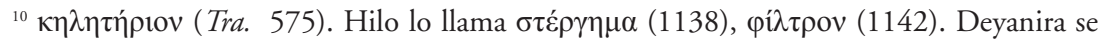

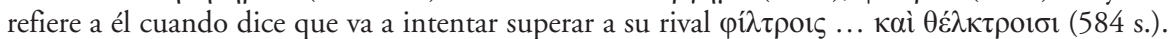

${ }^{11}$ No estaría justificado entender como alusión a un rito mágico lo que dice Deyanira en $580 \mathrm{~s}$.

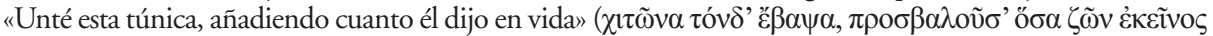
$\varepsilon i \tilde{i} \varepsilon)$. Deyanira se refiere a que, como explica más adelante, había seguido las indicaciones que Neso le había dado sobre la conservación del filtro (680-688). El escoliasta entiende el participio referido a la mezcla indicada por el centauro (vid. la nota anterior).

${ }^{12}$ Por eso valía solo para Deyanira. Las versiones que dan Diodoro Sículo y Apolodoro hacen esto más explícito, pues hablan no solo de sangre, sino también de semen: ella debe recoger el semen del centauro moribundo y mezclarlo con su sangre y con aceite (D. S. IV, 36, 5); con su sangre (Apollod. II, 7, 6).

${ }^{13}$ Aesch., Choeph. 1049 s. Según Pausanias (I, 28, 6), Esquilo fue el primero en representarlas con esa cabellera.

${ }^{14}$ Vita Aesch. 9 (= TrGF III, T 1, 30-32). El testimonio debe de provenir de una fuente peripatética, cf. Ercoles, 2018: 307 s., con bibliografía. El biógrafo, hablando de las causas que movieron

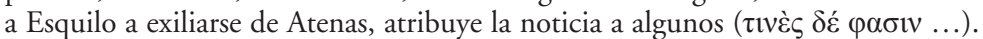

${ }^{15}$ Poll. IV, 110. Hasta entonces el coro trágico habría tenido cincuenta miembros.

${ }^{16}$ El poeta imita el estilo repetitivo propio de las cantilenas de los encantamientos. Cf. Romilly, 1975:13, García Teijeiro, 1993: 9. 
de Orestes (566-777), en el cual las Furias actuarán como acusadoras. Faraone ha mostrado la conexión de este pasaje con los maleficios destinados a "atar" las facultades físicas y mentales de la parte contraria en un juicio, con el fin de que no pueda defenderse ${ }^{17}$.

Con frecuencia las menciones son mucho más escuetas y algunas traslucen

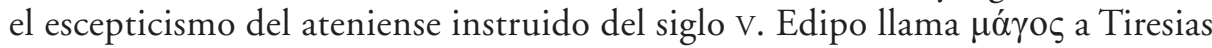
con desprecio, contraponiendo sus malas artes con el mérito del verdadero adivino $(\mathrm{S} ., \text { OT } 387 \text { s. })^{18}$. En el país de los tauros un mensajero cuenta que Ifigenia, para aparentar que estaba haciendo un ritual imponente, lanzó un alarido y se puso a entonar cantos bárbaros, actuando como una maga ${ }^{19}$ (E., IT 1336-1338). Ifis proclama su aversión contra quienes quieren alargar la vida con comestibles, con bebedizos y con remedios mágicos ${ }^{20}$ (E., Supp. 1109-1111). En su agitado relato un siervo frigio alude al supuesto poder de los magos para hacer invisible: Helena, perseguida por Orestes y Pílades, desapareció de pronto «o por pócimas o por escamoteo de magos ${ }^{21}$ o por arrebato de dioses» (E., Or. 1495-1498). Para pedir a Tecmesa que actúe con decisión, Ayante menciona los ensalmos en una expresión figurada: «No es de buen médico entonar ensalmos ${ }^{22}$ para curar un mal que requiere amputación» (S., $A j$. 581 s.). Hermíone acusa a Andrómaca de hacerla infértil con drogas secretas ${ }^{23}$ y esta se queja de la acusación (E., Andr. 32 s., 157 s., 205, 355 ss.). Medea, en cambio, prometía a Egeo una droga que lo haría engendrar ${ }^{24}$ (E., Med. 717 s.).

Referencias puntuales son también las del Hipólito de Eurípides, pero en él cumplen una función importante en la caracterización de los dos personajes femeninos. Fedra no es allí la madrastra lujuriosa de la tradición que se enamora de su hijastro y venga su desdén con una calumnia ${ }^{25}$. La diosa Afrodita le ha impuesto aquella terrible pasión, contra la que lucha con todas sus fuerzas. Como no puede vencerla,

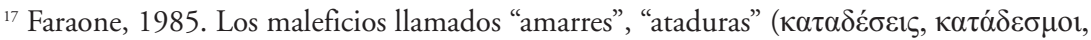
$\kappa \alpha \tau \alpha \delta \varepsilon ́ \sigma \mu \alpha \tau \alpha)$ son especialmente frecuentes en contextos judiciales. Pretenden conseguir que una potencia maléfica, entre otras las Erinis (Gager, 1992: 12), intervengan para "atar" a la víctima. En la tragedia de Esquilo son ellas mismas quienes practican el "amarre".

${ }^{18}$ Cf. Graf, 1997: 22,

${ }^{19} \mu \alpha \gamma \varepsilon v ́ o v \sigma$ ' es conjetura de Reiske comúnmente aceptada frente a $\mu \alpha \tau \varepsilon v ́ o v \sigma$ ' de los codd., que no da sentido. Cf. Graf, 1997: 24.

${ }^{20}$ El verso está dañado en la tradición directa. Plutarco, Mor. 110 C., ofrece una lectura aceptable.

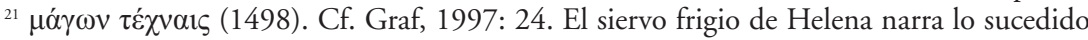
en metros líricos, lo cual es excepcional en personajes de baja condición.

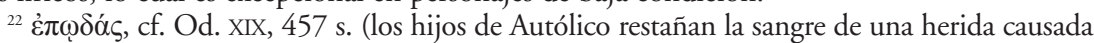
a Odiseo por una jabalí). Cf. Eitrem, 1941: 40 s., Graf, 1997: 28 s. En el pasaje de la tragedia la expresión equivale a «no se puede andar con paños calientes en asuntos muy graves». En Trach. 1000 Sófocles usa ảoı ó

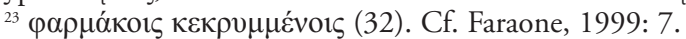

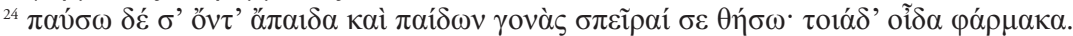

${ }^{25}$ Sobre la contraposición de la Fedra tradicional y la de esta tragedia, vid. Molinos Tejada y García Teijeiro, 2020. 
se resigna a dejarse morir de inanición sin contar a nadie su mal de amores. Quien desencadena la tragedia es su nodriza, mujer fiel y de mucho carácter. Toda la primera parte del drama está dominada por sus iniciativas para averiguar primero la naturaleza de la enfermedad que está matando a su señora y para intentar después desesperadamente salvarla contando a Hipólito la verdad. Su modo de ser, impaciente, mucho más inclinada a actuar que a reflexionar con calma, se manifiesta pronto. La referencia que hace a la adivinación al comienzo de su diálogo con Fedra es, en realidad, una exclamación después de un reproche. Impaciente porque aquella, en vez de explicarle qué le ocurre, divaga delirante sobre su anhelo de andar por montes y praderas, cazar, correr a caballo sobre los bancos de arena, se queja de esos desvaríos y exclama «Mucha adivinación haría falta para saber qué dios te descarría ${ }^{26}$ y te trastorna el juicio, niña» (236-238). No expresa un razonamiento ordenado: Fedra está loca, la locura habrá sido promovida por un dios, hay que consultar a un adivino para saber cuál. Simplemente pierde la paciencia porque no puede entender las incoherencias de su señora. Prosigue, sin embargo, intentado averiguar la verdad y llega a preguntarle si tiene sus manos manchadas de sangre. Cuando Fedra responde que la mácula está en su mente, sospecha alarmada que puede ser víctima de un maleficio: «¿Será un mal que haya atraído contra ti algún enemigo? $\aleph^{27}$. Posibilidad particularmente inquietante para una nodriza, entre cuyas preocupaciones estaba la del proteger al niño del mal de ojo y de los ataques mágicos ${ }^{28}$.

Los otros dos pasajes de esta tragedia que nos interesan se refieren a magia erótica. Cuando la nodriza consigue que Fedra confiese que está locamente enamorada de su hijastro, queda sobrecogida por la revelación, pero pronto se sobrepone. Comprende que la única manera de evitar que su señora muera es aceptar los hechos

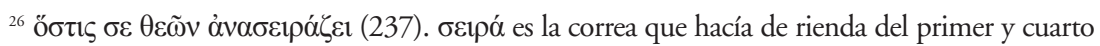
caballo de la cuadriga, que no iban uncidos al yugo (Poll. I, 141). Manejarlos bien era fundamental para hacer muy ceñidos los giros cuando se daba la vuelta a la meta o pilar que señalaba el fin de la pista de carreras, donde era fácil tener un accidente. Vid. Soph., El. 720 ss., y cf. Il. XXIII, 334 ss.

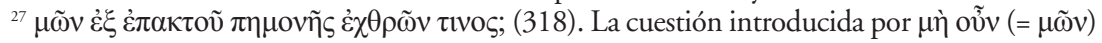

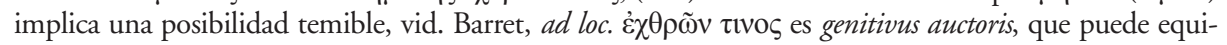

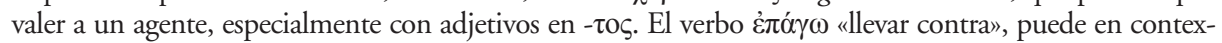
tos mágicos adquirir el sentido de inducir un mal contra alguien por medio de un espíritu o un hechi-

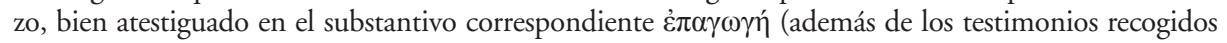
por Barrett, ad loc., cf. Thphr., Char. 16, 7; última línea en la tablilla de plomo de Falasarna de época

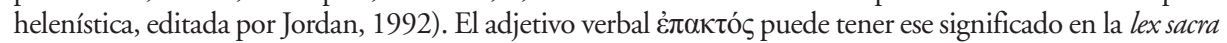
de Cirene (c. 325-320 a. C., CGRN99, 111, con bibliografía actualizada), menos probablemente en una defixión del s. II a. C. (Audollent, 1904: 8, 15). Cf. Maas, 1944.

${ }^{28}$ A ello se comprometía Deméter cuando, con aspecto de anciana, aceptó el encargo de criar

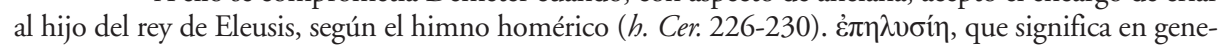
ral «ataque», debe de tener allí el valor especializado de «ataque mágico, hechizo». Hesiquio glosa la palabra

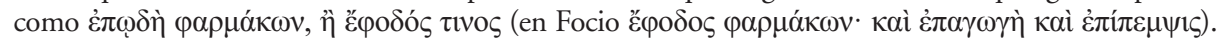
Además de los comentarios ad loc., cf. Kledt, 1996; Rakoczy, 1996: 150 s.; Garland, 2013: 210. La nodri-

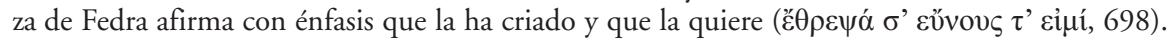


y buscar una solución desesperada. Ante todo, procura tranquilizarla con el argumento de que nadie puede resistir al amor, hasta los mismos dioses tienen que ceder ante él. Ella no ha de considerarse más fuerte que ellos, eso sería loca soberbia. Tiene que sobreponerse a su enfermedad. «Existen encantamientos y formulas mágicas, se hallará algún remedio para esta enfermedad», le dice ${ }^{29}$, hablando en términos generales. Ella no es experta y no sabe qué medicina puede ser esa, habrá que buscarla. Está, desde luego, intentando calmar la angustia de Fedra proponiéndole una esperanza, porque cuando esta condena los razonamientos engañosos y alaba, en cambio, los que alientan a mantener la honra, pierde la paciencia y afirma con franqueza brutal que lo que necesita ella no son palabras decorosas, sino al hombre, hay que contar enseguida a Hipólito lo que está pasando. No le hablaría así si no la viera en peligro de muerte (490-497). Sigue perseverando con fuerza y, cuando su señora le ruega que cese en su insistencia, pues tiene el alma tan quebrantada por la pasión que, si sigue oyendo aquellas tentadoras palabras, acabará por caer en lo que quiere evitar, aparenta haber encontrado una solución satisfactoria. Está, desde luego determinada a hablar inmediatamente con el hijastro, pero, para poder dejar a Fedra y entrar en la casa, menciona un remedio mágico que acaba de ocurrírsele (509-515):

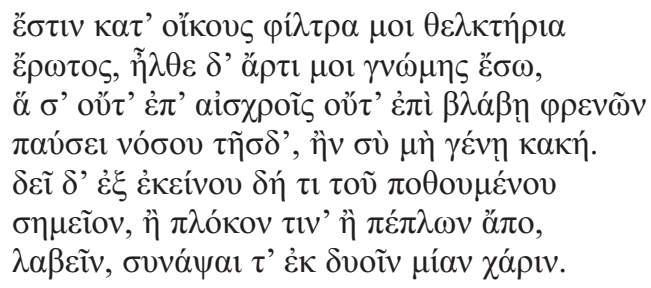

Tengo en casa filtros que hechizan al amor, acaban de venírseme a la cabeza, los cuales, sin infamia y sin trastornarte la mente, te curarán esta enfermedad, con tal de que no seas cobarde. Hay que tomar una prenda del hombre deseado, o un mechón de su pelo o un trozo de su vestido, y de los dos enlazar una sola dicha ${ }^{30}$.

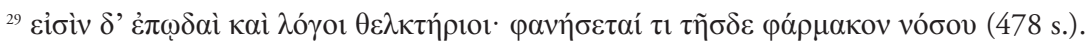

${ }^{30} \pi \lambda$ óкоv (514) es conjetura de Reiske generalmente aceptada por los editores. La tradición

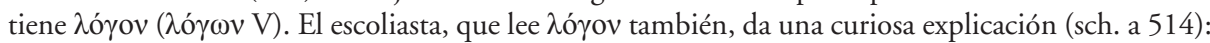
«Es preciso, dice, en el hechizo coger algo que represente a Hipólito, o una palabra suya recordada o un fragmento del borde de su vestido, y, uniendo la palabra de él con una palabra de Fedra, pronunciar el encantamiento; el fragmento de vestido, a su vez, hay que unirlo con otro fragmento de un vestido de Fedra, para que, en caso de fracaso utilizando la palabra, utilicemos el vestido. Unen, efectivamente, los dos, las palabras o los fragmentos de los mantos, y pronuncian una fórmula mágica de este tipo: "Que Hipólito, que ha dicho tal cosa, se enamore de Fedra, que ha dicho tal cosa"". Si la noticia no fuera, como parece, mera conjetura para obtener sentido de estos versos de Eurípides, sería un testimonio muy valioso del empleo de palabras y no de prendas materiales para representar a la víctima en los hechizos. 
Lo que la nodriza dice es poco coherente, por eso el pasaje se ha hecho sospechoso y algunos lo han considerado una interpolación ${ }^{31}$. Parece extraño, en efecto, que solo ahora recuerde que dispone de filtros amorosos, cuando muy poco antes se ha referido en términos generales a que se encontraría un encantamiento capaz de curarla. Habla además de ellos como si fueran un producto ya acabado, pero la indicación de que se necesitará algo que represente a la persona sobre la que han de actuar implica una preparación ritual, cuyo resultado sería precisamente la confección del filtro. No explica si se trata de un antiafrodisíaco, una medicina que cura el mal de amores, o un hechizo para atraer a la persona amada. Asegura que será inofensivo, pero afirma también que Fedra tendrá que ser valiente. La frase final es enigmá-

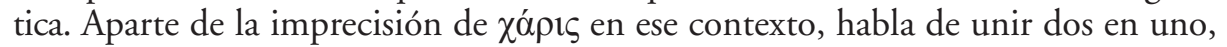
pero solo ha mencionado la señal o símbolo $(\sigma \eta \mu \varepsilon i ̃ o v, ~ 514)$ que represente a Hipólito, sin decir nada de otro que pudiera representar a Fedra. No se trata, pues, de la unión simbólica de los dos personajes. Barrett, en el comentario del pasaje, opina que se refiere a la unión del filtro y del símbolo, unidos para producir un solo resultado

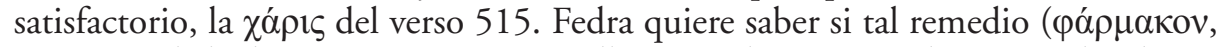
516) es un bebedizo o un ungüento ${ }^{32}$, y ella responde, contra toda verosimilitud, que no lo sabe, que piense solo en aprovecharse de él. Como no podía ser menos, su señora recela, teme que vaya a contarle a Hipólito lo que le ocurre, pero la nodriza, con una evasiva, entra en la casa para hacer precisamente eso (517-524).

La nodriza no pensó nunca en recurrir a hechizos para curar a Fedra. Enterada de cuál era la enfermedad que la aquejaba, comprendió que la situación era desesperada y que sería preciso intentar una curación desesperada también. La operación mágica con filtros y símbolo fue una ocurrencia momentánea, un pretexto para apaciguar por el momento a su señora y dejarla a ella libre para poner en práctica su temerario propósito. Tiene por eso los defectos de la improvisación y no resiste la comparación con los encantamientos amatorios que conocemos por los papiros mágicos. Para encontrar algo parecido en literatura hay que ir a buscarlos en géneros distintos de la tragedia.

\section{REFERENCIAS BIBLIOGRÁFICAS}

Audollent, A. (1904): Defixionum tabellae quotquot innotuerunt tam in Graecis orientis quam in totius occidentis partibus praeter Atticas in Corpore inscriptionum Atticarum editas, Paris.

BarretT, W. S. (ed.) (1964): Euripides, Hippolytus, Oxford.

${ }^{31}$ Vid. el aparato crítico actualizado de la edición de Roth, 2015.

${ }^{32}$ Barrett, en su comentario ad loc., considera que esta pregunta prueba que Fedra entiende que la nodriza le está hablando de un remedio contra su mal de amores, no de un hechizo para obligar a Hipólito a que la ame. Los encantamientos destinados a sujetar a la víctima al amor de otra persona, sin embargo, podían concretarse no solo en un bebedizo, sino también en un ungüento, como hemos visto en el caso de Deyanira, cf. Faraone, 1999: 7 s., 112 y n. 58. 
Broadhead, H. D. (ed.) (1960): The Persae of Aeschylus, Cambridge.

CGRN = J.-M. CARBON et alii (2016): A Collection of Greek Ritual Norms, Liège [http://cgrn.ulg.ac.be].

EITREM, S. (1928): «The Necromancy in the Persai of Aischylos», SO 6: 1-16.

EITREM, S. (1941): «La magie comme motif littéraire chez les Grecs et les Romaines», SO 21: 39-83.

ERColes, M. (2018): «The Imaginative Poet: Aeschylus’ Phantasiai in Ancient Literary Criticism: Homer, Hesiod, Pindar, and Aeschylus in Ancient Exegesis», en M. ErCOLES et alii (eds.), Approaches to Greek Poetry: Homer, Hesiod, Pindar and Aeschylus, Berlin, pp. 287-314.

ERrandonea, I. (1927): «Deianeira vere DEI-ANEIRA», Mnemosyne 55: 145-164.

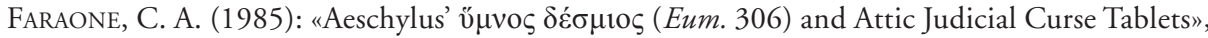
JHS 105: 150-154.

FARAOne, C. A. (1994): «Deianira’s Mistake and the Demise of Heracles: Erotic Magic in Sophocles' Trachiniae», Helios 21: 115-136.

Faraone, C. A. (1999): Ancient Greek Love Magic, Cambridge, Mass.

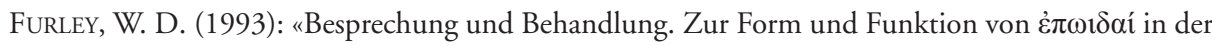
griechischen Zaubermedizin», en G. W. MosT et alii (eds.), Philanthropia kai eusebeia: Festschrift für Albrecht Dible zum 70. Geburtstag, Göttingen, pp. 80-104.

GaGer, J. G. (1992): Curse Tablets and Binding Spells from the Ancient World, Oxford.

Garland, R. (2013): «Children in Athenian Religion», en J. EvANS GRUBbS et alii (eds.), Oxford Handbook of Childhood and Education in the Classical World, Oxford, pp. 207-226.

GarCía Teijeiro, M. (1993): «El recurso a lo maravilloso en el teatro griego», en A. RuIz Sola et alii (eds.), Teatro clásico y teatro europeo, Burgos, pp. 7-12.

García Teijeiro, M. (2002): «La figura de la maga en las literaturas griega y latina», en Ma. J. GarCíA Soler (ed.), TIMH $\Sigma$ XAPIN. Homenaje al Profesor Pedro A. Gainzaráin, Vitoria, pp. 181-191.

García Teijeiro, M. (2005): «De maga a bruja: Evolución de la hechicera en la Antigüedad Clásica», en M. GonZÁlez GonZález - Ma. A. Pedregal Rodríguez, (eds.), Venus sin espejo: Imágenes de mujeres en la Antigüedad clásica y el cristianismo primitivo, Oviedo, pp. 33-53.

Graf, F. (1997): Magic in the Ancient World, Cambridge, Mass. [traducción reelaborada de La magie dans l'antiquité gréco-romaine, Paris 1994].

Headlam, W. (1902): «Ghost-Raising, Magic, and the Underworld», CR 16: 52-61.

JoRDAN, D. R. (1992): «The Inscribed Lead Tablet from Phalasarna», ZPE 94: 191-194.

JOUAN, F. (1981): «L'évocation des morts dans la tragedie grecque», RHR 198: 403-421.

KLEDT, A. (1996): «Zu den Versen 228-230 des homerischen Demeter-Hymnos», Philologus 140: 349-350.

Lawson, J. C. (1934): «The Evocation of Darius (Aesch. Persae 607-93)», CQ 28: 79-89.

LIMC = Lexicon Iconographicum Mythologiae Classicae, 8 vols. + 2 inds. + 1 supplem., Zürich, 1981-2009.

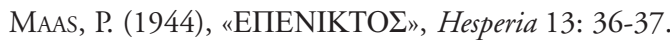

Macías Otero, S. (2015): «On the Threshold of Hades: Necromancy and Nekyia in Some Passages of Greek Tragedy», ÉC 83: 137-153.

Melero Bellido, A. (1996): «Les autres Médées du theâtre grec», Pallas 45: 57-68.

Molinos Tejada, Ma. T. y García Teijeiro, M. (2020): «La nodriza de Fedra», en Maa. C. Encinas REGUERO - J. BILBAO RUIZ (eds.), @EATPON KAI ZOH. Estudios de teatro griego en honor a la Profesora Milagros Quijada Sagredo, Madrid, pp. 171-182. 
Ogden, D. (2001): Greek and Roman Necromancy, Princeton.

PozzI, D. C. (1994): «Deianeira’s Robe: Diction in Sophocles' Trachiniae», Mnemosyne (IV serie) 47: 577-585.

RAKOCZY, TH. (1996): Böser Blick, Macht des Auges und Neid der Götter: eine Untersuchung zur Kraft des Blickes in der griechischen Literatur, Tübingen.

Romilly, J. DE (1975): Magic and Rhetoric in Ancient Greece, Cambridge, Mass.

Rose, H. J. (1950): «Ghost Ritual in Aeschylus», HThR 43: 257-280.

Rотн, P. (ed.) (2015): Euripides Hippolytos, Berlin.

SCHMIDT, M. (1992): «Medeia», en LIMC VI, 1: 386-398.

$\operatorname{Tr} G F=$ Tragicorum Graecorum Fragmenta, 1971-2004, 5 vols., Göttingen.

Wright, M. (2016): The Lost Plays of Greek Tragedy I: Neglected Authors, London.

WRIGHT, M. (2018): The Lost Plays of Greek Tragedy. Vol. II: Aeschylus, Sophocles and Euripides, London. 